\title{
Reflective self-study for an integrated learning approach to early childhood mathematics teacher education
}

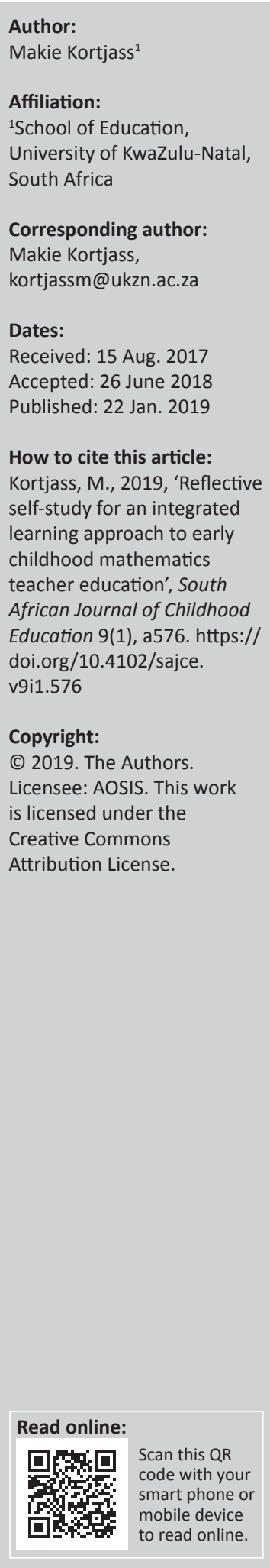

Background: This article gives an account of what I learned through the process of a self-study research project. Self-study teacher research allows teacher educators and teachers to improve their learning, plan new pedagogies and impact students' learning.

Aim: The aim of this self-study research was to improve my own practice in early childhood mathematics teacher education through interaction and collaboration with others, such as colleagues and students.

Setting: As a South African university-based teacher educator, I piloted an integrated learning approach (ILA) in the teaching and learning of early childhood mathematics in a selected undergraduate programme.

Methods: I began by tracking my personal development in mathematics education and in so doing was able to recognise my personal learning of mathematics as a child growing up in an African township context. I then worked with a class of 38 student teachers to create collages and concept maps to explore their understandings and experiences of ILA.

Results: Through this project, I discovered that colleagues in the role of critical friends provided essential feedback on my work in progress. I also learned that student teachers need to be equipped with knowledge and hands-on experience of how integration can take place in teaching and learning early childhood mathematics. I realised that it was essential to constantly reflect on my own personal history and my professional practice to explore new ways of teaching mathematics.

Conclusion: Teacher educators may consider engaging in self-study research that includes artbased self-study methods to reflect on their practices and see how they change for the benefit of their students and ultimately for the benefit of the learners.

\section{Introduction}

As a precursor to my doctoral study on the integrated learning approach (ILA) concept in the teaching and learning of mathematics in the Foundation Phase (FP), I piloted a project with 38 students in the bachelor of education (B.Ed.) programme at the tertiary institution where I am currently based. The discourse commences with an explanation of what is understood by an ILA in the teaching and learning of early mathematics in the FP. I then describe how the sociocultural theoretical perspective was used in cultivating an ILA among student teachers. A description of the research methods and design follows. My personal acquisition of basic mathematical skills during my early childhood is traced and I explain how the games we played as children in a township enhanced mathematical concepts. I then provide an account of my experiences of working with student teachers using art-based methods such as collages and concept maps. I also highlight my interactions with critical friends (i.e. peer-support reviewers) and the importance of constantly reflecting on my practice by recording my observations and reflections in a journal. This facilitated the exploration of new ways of teaching mathematics through collaboration with my colleagues. In conclusion, I consider how and what I learned through my interaction with 'critical friends' and how an ILA that had been followed assisted me in developing reflexive self-awareness strategies that enhanced my skills as a teacher educator and will continue to do so in the future.

Currently, I am a lecturer at a higher education institution in KwaZulu-Natal. My decision to undertake a self-study research approach was prompted by both a personal and professional motivation to cultivate a desire among my students to embrace an ILA to teaching mathematics in the FP. This desire was underpinned by reflections on my experiences as a teacher in the FP and 
as a lecturer at a college of education and a higher education institution. Assisting young learners in the acquiring of early mathematical skills lays a critical foundation for later success in mathematics (DBE 2011). I have observed that student teachers experience some problems regarding the use of mathematics language, the knowledge and teaching of basic number and geometric concepts.

The pilot study that I launched as a precursor to my doctoral study explored strategies that could be used to cultivate ILA awareness among first-year student teachers in the module Mathematics in the Early Years. It was envisaged that the implementation of ILA would enhance student teachers' understanding of curriculum integration and that this would enable them to integrate their teaching of the Mathematics learning area with the Languages and Life Skills learning areas rather than teaching it in isolation. According to Adamu (2003:3), curriculum integration 'focuses on making learning reflect life so that students see the value of what they are taught'. Through this process, content and skills are presented in such a way that learning becomes more relevant and meaningful because a link is established between skills and content that surpasses curriculum lines (Adamu 2003). In this context, I envisaged that the student teachers would learn how to implement appropriate educational approaches that would prepare learners for lifelong learning.

The pilot study aimed to address three research questions:

- What can I learn from my personal history that will support the cultivation of an ILA to mathematics in the FP among my student teachers?

- What can I learn from working with student teachers using arts-based methods that will support the cultivation of an ILA to mathematics in the FP among my student teachers?

- What can I learn from working with critical friends about cultivating an ILA to mathematics in the FP among my student teachers?

\section{An integrated learning approach in the Early Childhood Bachelor of Education programme}

Combining disciplines and pedagogical approaches in higher education is not a new phenomenon. Adamu (2003:1) defines an integrated curriculum as 'an educational approach that cuts across and draws on multiple subject areas for learning and instruction'. Adamu (2003) argues that curriculum integration requires that educators consider education as a process of developing the abilities of learners for the 21st century, ensuring that the content is somehow integrated. The aim of an integrated teaching and learning approach is to provide students with more meaningful experiences.

Students who intend to become teachers by obtaining a B.Ed. degree can specialise in teaching in any one of the following phases: the FP; the Intermediate Phase; the Senior Phase; or the Further Education and Training band of schooling.
According to the Revised Policy on Minimum Requirements for Teacher Education Qualifications, the B.Ed. degree has the key purpose of providing a well-rounded education that prepares graduates with the essential subject content knowledge and methodology that will allow them to demonstrate competence and responsibility as academically and professionally qualified novice teachers (Department of Higher Education and Training 2015). Foundation Phase programmes are aimed at preparing students to teach from Grade $\mathrm{R}$ to Grade 3. The mathematics module is one of the specialisation modules that FP students do for their B.Ed. degree.

The Department of Basic Education (2011) foregrounds an integrated approach among the learning areas in the FP Grade R onwards. The teaching and learning methods in the FP are often different from those employed in the Intermediate and Senior phases. This is because Grade $\mathrm{R}$ is the first 'formal' year of teaching and learning and therefore requires playbased pedagogy and because it is linked with Grades 1-3. Because Grade $\mathrm{R}$ as the first 'formal' year of teaching and learning requires play-based pedagogy and because it is linked with Grades 1-3, the teaching and learning methods in the FP are often different from those employed in the Intermediate and Senior Phases. For example, FP teachers need to incorporate significant elements of play into their teaching. The benefits of play for children's early development have been emphasised through research (Ramani \& Eason 2015). To illustrate, when Mathematics and Life Skills learning areas are integrated, learners use their bodies in physical education lessons when playing a game such as hopscotch, which enhances the concepts of square and circular shapes. Moreover, while they are playing, their counting skills improve. The Curriculum and Assessment Policy Statement (CAPS) states that Life Skills is a 'cross cutting subject that should support and strengthen the teaching of other core FP subjects, namely Languages (particularly Home and First Additional) and Mathematics' (DBE 2011:8).

According to Ramani and Eason (2015), FP teachers need to use various teaching strategies and a variety of representations such as pictures and models to teach and reinforce concepts. Many listening and speaking skills, as well as vocabulary building skills, are thus developed within the Mathematics and Life Skills curricula. These authors also argue that teachers 'can integrate mathematics into language arts class[es] by discussing and building on the math content in many children's books' (Ramani \& Eason 2015:31). Guided play activities can also link mathematical, linguistic and Life Skills and are powerful tools to stimulate learning. However, Hughes (1986) argues that many learners do not experience mathematics as a 'language' with which they are at home; rather, they view it as foreign concepts that they have to acquire, which often causes resistance. For example, 'words and phrases such as "difference", "times", "borrow", "carry" and "goes into" are all part of the vocabulary of arithmetic that learners have to make sense of' (Hughes 1986:42). Foundation Phase teachers therefore need to be consciously 
aware of the language they use so that their learners are not hindered in the process of grasping mathematical concepts.

\section{Theoretical perspective}

According to Lake (1994), the drive towards an integrated curriculum is cemented in learning theorists' arguments that promote a sociocultural view of learning. I thus adopted a sociocultural theoretical perspective in cultivating an ILA model that could be used by my student teachers. I drew on Vygotsky's sociocultural perspective, which is based on the principle that understanding is socially motivated by other people that we come into contact with (Dimitriadis \& Kamberelis 2006). According to Vygotsky, children are active learners and for this reason one cannot separate individual learning from the social context. Likewise, Lee (2014:1039) argues that 'the sociocultural dimension is an important part of teaching and learning because education systems [and] classroom teaching and learning are neither culture nor context free'.

When adopting a sociocultural theoretical perspective, teachers and teacher educators need to be consciously thinking of the means that can be employed to ensure that learners and student teachers get ample opportunities for making sense of everyday experiences. To illustrate this point, Hughes (1986:42) argues that a lack of context in the use of words such as 'make' and 'take away' when asking a question such as 'what does one and two make?' may confuse learners. Therefore, meaningful teaching of mathematical concepts should involve real-life situations. Lee (2014:1039) claims that the learning of so-called difficult subjects such as Science and Mathematics cannot be avoided and that they are affected at varying levels by the sociocultural backgrounds of learners and teachers, [and by] the political and sociocultural and the broader global education environment'. I concur with this view and feel strongly that Science and Mathematics are often labelled as difficult subjects simply because the methods and resources that are used to teach them neglect the use of familiar concepts and concrete objects that will facilitate learning. It is in this context that Lee (2014) insists that teachers should make use of the knowledge that learners use every day when they are engaged in activities to master scientific and mathematical concepts. Thus teachers need to consider how their own practical experiences in acquiring scientific and mathematical skills may be used to enhance their personal knowledge base and pedagogical practices. Vygotsky acknowledged the importance of the relationship between learning and the child's social and cultural worlds (Dimitriadis \& Kamberelis 2006). Lee (2014:1041) has claimed that such skills may be used to assist learners in 'crossing the border between their own culture and the culture of science', which naturally includes the acquisition of mathematical concepts.

The above arguments encouraged me to embrace the concept that FP teacher educators and teachers need to take into account the sociocultural context of learners in order to make the acquisition of mathematical skills a social experience.
This may be done through the use of cultural and everyday resources that are familiar to teachers and learners. Berk (2013) emphasises the strong effects that rich social and cultural contexts may have on children's thinking. Foundation Phase teachers therefore need to be knowledgeable about the different sociocultural factors that will impact the way they teach and respond to their learners, as well as the way in which learners learn in class (Berk 2013). Dimitriadis and Kamberelis (2006:192) note that Vygotsky's sociocultural theory suggests that 'parents, caregivers, peers and the culture at large [are] responsible for developing higher order functions' (2006:192). This implies that children's thinking is shaped by their participation in the social community and that these experiences should be harnessed to enrich learning processes.

Vygotsky also developed the advanced idea that human cognition is fundamentally based on the social world and on language (Berk 2013). Vygotsky also argued that learning is mediated through tools. Wertsch (1985) (as cited in Samaras 2010) concurs and alludes to how humans' use of tools such as language and the arts is a product of sociocultural development and that these tools are inherently located in interactional, cultural, institutional and historical contexts. Vygotsky also saw language as the foundation for problem-solving and abstract reasoning, as it assists children to think about activities and behaviour (Berk 2013). Using the sociocultural perspective as a lens, it may thus be argued that learners learn most efficiently by using tools such as language and that they solve problems by using resources that are accessible to them in their environment (Conkbayir \& Pascal 2016). It is therefore imperative that learners be afforded opportunities to construct their understanding of the world through interactions with other learners and adults through the use of language and other resources; only then will they make sense of their environment and their place in the world (Conkbayir \& Pascal 2016). It is therefore inevitable that FP learners' understanding of mathematical concepts, their ability to solve problems and their attitude towards mathematics are influenced not only by the resources that they are encouraged to use but also by the language that they encounter in the mathematics classroom.

Vygotsky also highlighted the 'zone of proximal development' (ZPD) by emphasising the role played in children's learning by people such as parents, other adults, teachers, coaches and even children and friends (Dimitriadis \& Kamberelis 2006). Conkbayir and Pascal (2016:80) explain that the ZPD 'is just one way in which adults support children to problem solve and achieve independence during learning experiences'. Dimitriadis and Kamberelis (2006) further explain that Vygotsky used the term 'learning' to describe the important shifts in growth and behaviour in children. Thus recognition of the ZPD necessitates that the practitioner (or another adult or capable peer) observes and identifies children's abilities and 'develops strategies to help them move on to a higher level of understanding' (Conkbayir \& Pascal 2016:81). 
Foundation Phase teachers should therefore plan and provide appropriately structured experiences so that learners gain new knowledge and skills to reach increasingly higher levels of understanding. It is in this context that I argue that the ILA should play a significant role when learning activities are planned so that learners may acquire and develop new concepts and skills meaningfully.

\section{Research setting and participants}

This study was conducted over a 6-month period (a semester) at a South African university in the province of KwaZuluNatal. The campus at which the study was conducted specialises in undergraduate to postgraduate teacher education. It accommodates student teachers from diverse socio-economic backgrounds, race groups, social demographics, and rural and urban areas. The language of teaching and learning is English. However, student teachers are expected to acquire bilingual language proficiencies and be aware of the importance of a multicultural society and the roles that teachers can play in facilitating awareness and skills in this regard. Because the majority of the students are isiZulu speakers, student teachers are learning in their first additional language, which is English.

I was the primary participant in this self-study project in which I explored the cultivation of an ILA to teaching mathematical skills in the Early Years module. The secondary participants in the study were 38 first-year student teachers enrolled for the B.Ed. FP programme.

\section{Research methods and design}

According to Samaras (2011:15), 'self-study teacher research is an empowering research methodology for teachers that holds much promise for educational reform'. I employed a self-study research methodology in this project as my aim was to examine and improve my practices in teaching FP students the ability to teach mathematics in this phase. LaBoskey (2004) argues that when teacher educators aim to improve their practice and focus on an improved understanding of their educational contexts, it may result in an enhanced understanding of their teaching practices. LaBoskey (2004) also points out that teacher education research seeks to address best practices in preparing new teachers and facilitating ongoing teacher development. Samaras (2011) concurs, arguing that teachers who engage in self-study projects are inspired to improve their practice in order to help their students improve their learning. Selfstudy is about learning from the experiences that are embedded within the abilities of teacher educators and teachers, and this creates new experiences for themselves and for those whom they teach. This research approach allows teacher educators and teachers to improve their learning, plan new pedagogies and impact students' learning (Samaras 2011).

A self-study research approach was thus appropriate for this pilot project as I sought to improve my practices and inspire my students to adopt an ILA in their classrooms. I undertook self-study research to enable others to understand learning from experience by showing them how they could do it themselves, as suggested by Russell (2002) (as cited in LaBoskey 2004). I also took cognisance of the fact that although self-study research focuses on an exploration of the researcher's own practices, interaction and collaboration with others, such as colleagues and students, is imperative (LaBoskey 2004).

\section{Self-study methods and data generation}

Numerous self-study methods have been developed by and for self-study teacher educators (Samaras 2011). In this study I drew on two self-study methods to respond to my research questions, namely the personal history and the arts-based self-study methods. Data were also generated through journal writing and critical reflection.

\section{Personal history self-study method}

I began by tracking my personal recollections of developing mathematical skills and was thus able to draw from my experiences of learning mathematical concepts as a child growing up in an African township. According to Samaras (2011:284), the personal history self-study method is 'a selfstudy method to explore how personal experiences, culture, history, and learning experiences can inform one's teaching'. Correspondingly, Schuck and Russell (2005) term this approach the 'personal experiences method'. I anticipated that utilising this method would assist me in establishing how my lived experiences influenced my teaching. Samaras (2011:95) notes that this approach is mostly beneficial in examining 'who you are as a teacher, your teacher identity, the motivations behind your teacher goals, and the constraints and supports you have experienced in reaching those goals'. I thus endeavoured to become more aware of my background as a teacher educator and to determine how my experiences and insights influence what I did as an educator.

I delved into personal recollections of my experiences of early childhood acquisition of mathematical concepts and recorded these reflections in a journal. I also took photographs that depict my memories of my experiences of early childhood mathematical concepts. I did this because Weber (2014) asserts that visual images compel us to take a step back and look at our practice from the new viewpoint provided by the medium itself, as such items enhance the potential for a deeper self-analysis.

\section{An arts-based self-study method}

The artistic mode is another major self-study approach (LaBoskey 2004). Arts-based self-study methods help researchers to reflect, investigate and engage in dialogue about improving their teaching through the arts (Samaras 2011). I decided to use arts-based methods in teaching the Early Years Mathematics module as I could thus integrate 
mathematics with other learning areas. In this approach that was based on visual art, I encouraged the students to utilise collages and concept maps to enhance their knowledge and understanding of the subject matter, as the visual art tool incorporates various ways in which meaning can be created through artistic forms of expression (Weber 2014). Visual methods assist researchers to 'keep their own and their students' bodies in mind and push for more sophisticated analysis and theorising that considers [sic] learning and teaching ...' (Weber 2014:11). The student teachers therefore created collages and concept maps to explore and illustrate their understanding and experiences of an ILA to teaching mathematical concepts in the FP.

\section{Working with student teachers in creating collages and concept maps}

Self-study researchers interact with their students in a variety of ways. For example, students' work may be used as 'a primary data source' for interpretation and analysis (LaBoskey 2004:849). According to Butler-Kisber and Poldma (2010:2), creating a collage is the process of using fragments of found images or materials and gluing them to a flat surface to portray phenomena', whereas concept mapping is a 'diagrammatic and visual means of expressing ideas held in the mind'. Such diagrams are designed to visually connect and link ideas among various concepts.

To involve the student teachers in creating collages, I divided them into three groups. I gave each group a different colour chart that also represented their group names. The red, orange and yellow groups each pasted the images that they collected on charts of the same colour. Each group had to consider the following questions for procuring the images: 'How can we integrate the Mathematics learning area with Languages and Life Skills in the FP?' and 'How can we integrate mathematical concepts or content areas with one another within the Mathematics learning area?' Magazines were perused and about 12 main images were collected per group. These images were cut out and pasted onto the charts to illustrate the connections and concepts the groups wished to illustrate meaningfully. Butler-Kisber and Poldma (2010:3) maintain that cutting and sticking are basic skills that have been developed early in life and this practice has 'become part of everyone's repertoire', so 'a collage can be done by novices while acquiring more sophisticated aesthetic and compositional expertise'. The interactive collage-making process (see Figure 1) encouraged the student teachers to reflect, plan and deliberate on how integration could occur across the learning areas in the FP.

In the following lesson, student teachers transposed the meaning or message of their collages by creating concept maps. Butler-Kisber and Poldma (2010:6) explain that concept maps 'are created using hand-drawn sketches or virtual tools in a non-linear and visual format by drawing on paper to show the thinking as it emerges'. By creating these concept maps, the students were able to make connections across the concepts that were illustrated by the collages. In this manner they explored and gave direction to an ILA. The students understood that making collages and creating concept maps were ways of communicating their ideas and formulating an interactive approach to learning that will assist their learners to understand the concepts they will teach (Butler-Kisber \& Poldma 2010). They also understood that the concept mapping process may serve as a method to reorganise ideas, which will limit the use of text to brief words or phrases (Weber 2014). The visual impact of these collages and maps was also deemed highly appropriate for learning in the FP, particularly because the images related to children's early experiences of the world around them while demonstrating particular mathematical concepts. It is noted at this point that while the students were engaged in the creation of these collages and concept maps, I meticulously documented my observations and reflections in a journal.

\section{Working with critical friends}

This project was particularly successful because knowledgeable colleagues in the role of critical friends provided essential feedback on my work while it was in progress. Samaras (2011) describes critical friends as:

trusted colleagues who seek support and validate the research of another colleague so that the latter person gains new perspectives
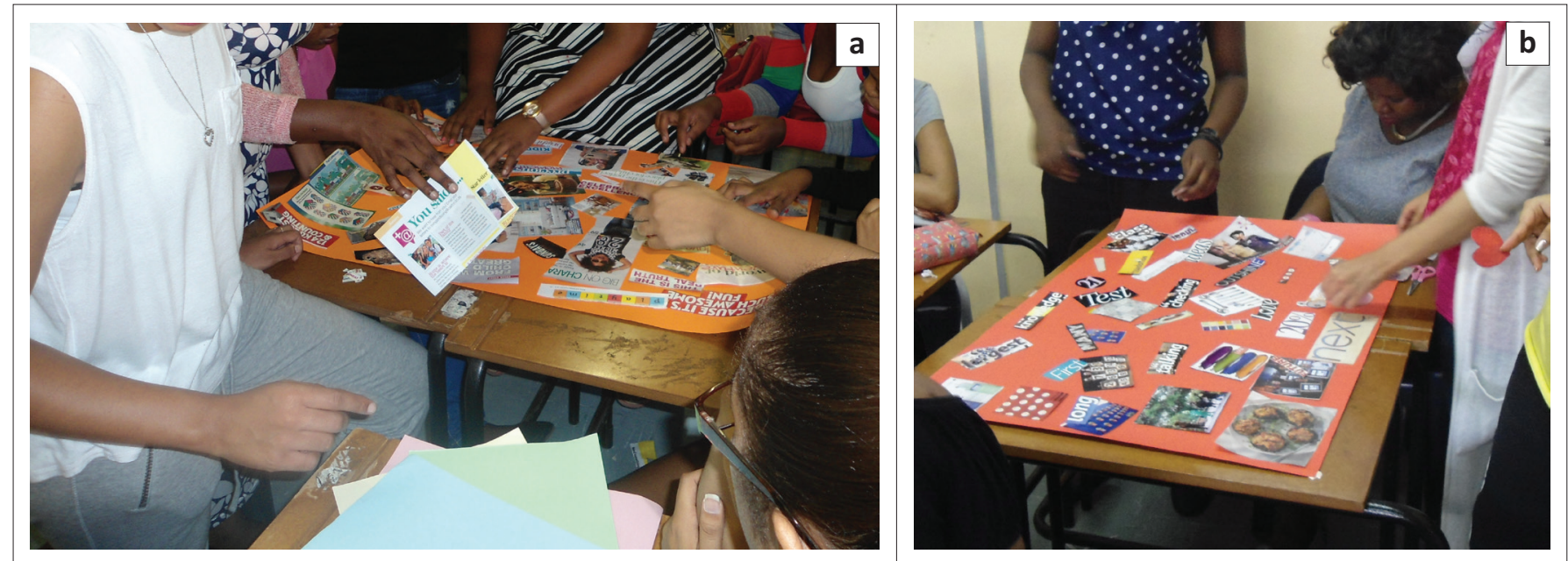

FIGURE 1: Student teachers engaging in the process of making a collage in a and $\mathrm{b}$. 
and understanding and may reframe their interpretations of a topic under investigation. (p. 281)

LaBoskey (2004) argues that self-study researchers collaborate with critical friends near and far who are working on different professional practice agendas. Because self-study has to be interactive, I presented my research to trusted colleagues in different contexts. For example, I presented it to a group of colleagues who were lecturers from different disciplines but who also conducted self-study research on a regular basis. I also presented my project at a national conference on education. I received feedback from these two groups and I audio recorded the discussions.

\section{Analysis}

I perused the data that I had generated and re-read the transcripts of the presentations, discussions and reflections a number of times in order to reflect on what I was learning. The data were analysed inductively with reference to the learning zones and the zones of possibility. In this process I paid attention to 'any repeated statements, behaviours and actions across the data set' (Samaras 2011:199). Kravtsova (2006) (cited in Samaras 2011) states that a zone of possibility occurs when the teacher and learners are learning in order to gain other perceptions through their discussions. I also took cognisance of the criticisms that were offered by my reviewers (or critical friends) regarding the ILA that I was following.

Nieuwenhuis (2010) emphasises that when the researcher works inductively with emergent categories, he or she needs to read through the identified codes and find the themes that recur in the data. By adhering to this process, I identified themes and patterns that emerged in response to my research questions. I colour coded the themes that emerged from the data. For example, one comment that emerged from the transcriptions of my critical friends' response was that 'mathematics may be lost' if there is an overemphasis on the ILA. Based on Samaras' (2011) suggestions, I fitted the analysis procedures with the methodological position of my study and consistently and coherently managed the analysis and interpretation process according to the principles of the study design. I also considered how the data connected across the full data set 'by recognising important links that connect the data together' (Samaras 2011:207).

Pinnegar and Hamilton (2009) (cited in Samaras 2011) emphasise that a researcher is an interpreter, a meaning maker and a theory maker. Therefore, the purpose of improving my practice through constructing meaning rather than by making any final claims of knowing was crucial (Samaras 2011).

\section{Ethical considerations}

Ethical clearance to conduct this study was obtained through the appropriate channels (ethical clearance number: HSS/0178/016). I also explained to the students what my study would involve and they agreed voluntarily to sign consent forms and to commit to the study. The students could withdraw at any time and their confidentiality was attained through the use of pseudonyms. The participants were aware that the information they provided would be used for research purposes only. The activities that the student teachers engaged in formed part of their classwork for the Mathematics in the Early Years module. All student teachers were required to participate in the class activities irrespective of whether they agreed to participate in the study. All the students in this group participated and consented.

Addressing issues of ethics was crucial in this self-study research project, particularly because I was both a researcher and a teacher educator with a pedagogic responsibility towards my students who assisted me in working towards improving my practice. Samaras (2011) notes that one has to be aware of the delicate position of these two roles to ensure that their positionality does not affect the students adversely. Moreover, conducting research in an ethical manner improves the quality of research and contributes to its trustworthiness (Samaras 2011).

\section{Results and discussion}

\section{Using my personal history and experiences as a basis for the teaching of mathematics in an integrated learning approach}

In this section I discuss how my childhood experiences of acquiring mathematical skills addressed the first research question: 'What can I learn from my personal history in order to cultivate an ILA to Early Childhood Mathematics Education?' I simulated two of the games we played as children and took photographs to illustrate what I remembered about these games.

\section{Amagende - The stone game}

I grew up in a township and I remember how we enjoyed playing different games in the street and in the backyard of our home. Without being aware of it, these games taught us basic mathematical skills as we were growing up. Amagende was a game that we played with stones (or pebbles) before we entered school. The concept is illustrated in Figure 2.

Two to six players could play the game. We would sit in a circle with a big pile of stones (or pebbles) in front of us. We would draw a circle around the stones called isibaya [kraal]. Each player would pick one stone (ingede) to play with and would toss it into the air while dragging a portion of amagende (stones) from the circle. The player has to grab ingede as it comes down, throw it up again and push amagende at the same time into the circle (isibaya), leaving out one (Mweli 2018). The one left outside now belongs to that player. If the player drops ingede, then it is the next player's turn. The same pattern continues until amagende are finished from the circle. The next levels of the game involve the players leaving two, three, four stones and so on. The winner of each level is the player who collects all the stones first. The stones were thus 


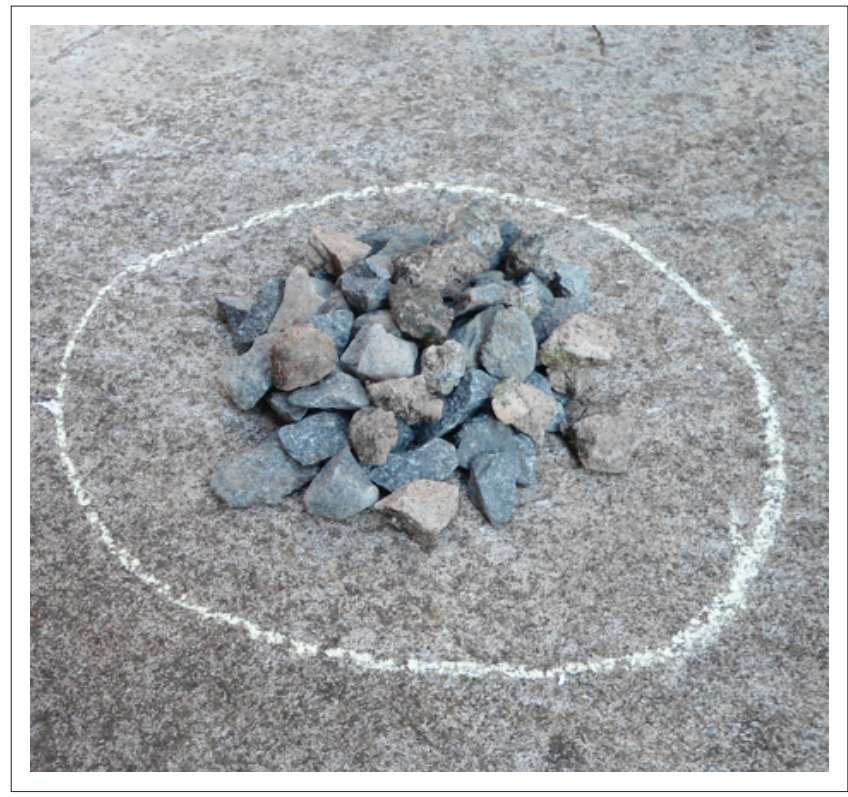

FIGURE 2: Heaped stones in a circle.

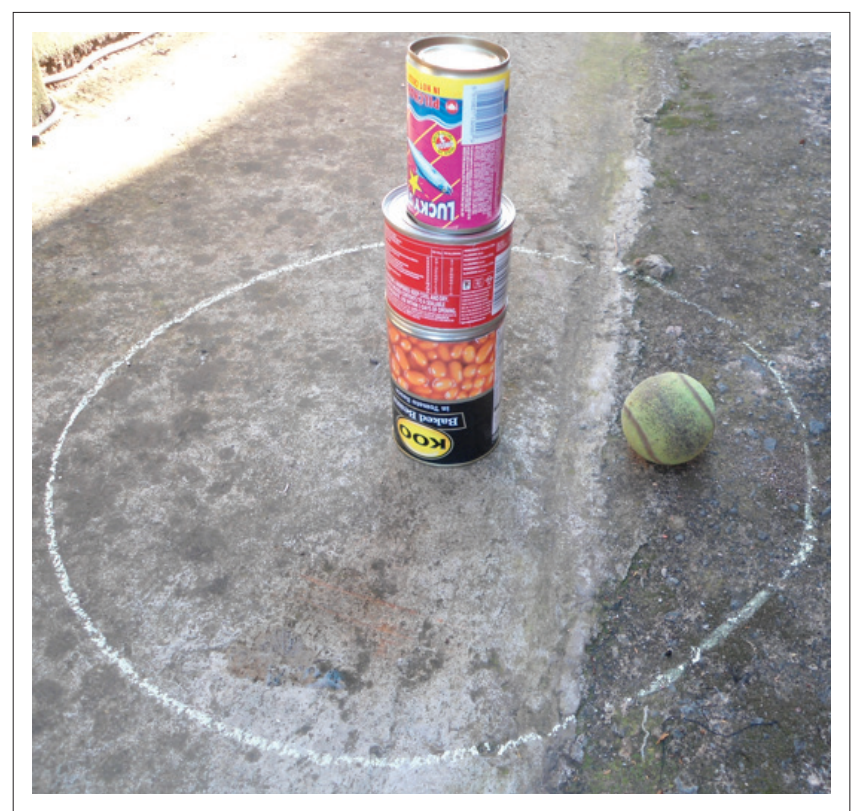

FIGURE 3: Three tins

counted to see who had managed to collect the most, which was a significant learning experience in terms of mathematical concepts.

Another game that we played involved three ordinary canned food tins, as depicted in Figure 3.

This popular game was called 'three tins' and was played in the street. We would stack three tins, one on top of the other. We would then draw a circle around them and draw a line a few metres away from the circle. Two teams would be involved - the attacking and defending teams. The attacking team would throw a tennis ball and try to hit the tins so that they would come tumbling down. The thrower would then run towards the circle and reset the tins within the circle. Each player had three attempts to hit the tins. While this was happening, the defending team would run to retrieve the ball and then throw the ball, aiming to hit the attacker. A hit would mean that the attacker was out, just like hitting the wickets of a cricket player. If the attacker was able to reset the tins without getting hit, a point was scored. All the members of a team were given a chance to attack, while the defenders were placed strategically around the area of the tins (almost like a game of cricket). The idea was to aim and throw the ball as hard as possible at the tins, thus allowing the ball to bounce far away and giving the attacker a chance to reset the tins. Mathematical concepts were strengthened when hits were scored and counted.

\section{Learning through recalling childhood games}

Looking back through a sociocultural theoretical lens, I can see how, by playing these games, we acquired counting and number skills using everyday objects such as pebbles and discarded tins. Nkopodi and Mosimege (2009) acknowledge that numerous mathematical concepts are engendered by various childhood games that can be related to various content areas of mathematics. Gerdes (1998:46) notes that mathematics is 'a universal activity; that is, it is a pan-cultural and pan-human activity. In all cultures mathematical thinking takes place, whether spontaneously or in an organized way'. This suggests that student teachers should learn about different cultures in order to understand the diversity of the learners that they will work with and the knowledge they may have acquired. In this context, Gerdes (1998) suggests that people:

may be doing mathematics, may be engaged in thinking that involves mathematical thought processes without themselves calling their activity 'mathematical'; they may even say that they do not know mathematics, or that they are not able to do mathematics. (p. 48)

As children, we learned about turn taking and sequencing in our games without being aware of it. By playing games, children learn to count, add and subtract without consciously thinking about these skills as being the basis of mathematics. Although they may differ in nature and application, games are universal among children of all sociocultural contexts where mathematical concepts are first acquired, which challenge the subjective notion that subjects such as mathematics and sciences 'are associated with western culture and are never linked with African culture' (Nkopodi \& Mosimege 2009:377).

The above arguments clearly imply that teacher educators at tertiary level who lecture in the field of mathematics need to take into account the sociocultural contexts of their students. By being conscious of this reality, lecturers will inspire their students with the insight that the acquisition of mathematical concepts is a social experience in which learners should participate actively. Moreover, resources that are familiar to student teachers should be used. By engaging students in practical activities, they may be able to assist learners in 'crossing the border between their own culture' and the culture of mathematics or science (Lee 2014:1041). 
Upon reflection, I was able to see that numerical values as well as counting, addition and subtraction skills are developed through childhood games. Therefore, to create a meaningful learning environment in which student teachers can develop their own understanding of the pedagogy that will be required to teach their learners, it is important that teacher educators take into account what their students already know and build on this knowledge (Nkopodi \& Mosimege 2009). This exploratory investigation transformed the way that I used to comprehend teaching and learning of mathematical skills in FP teacher education, and I was able to impart this knowledge to my students to capacitate them to do the same as teachers in the classroom one day.

\section{Learning from working with student teachers}

This section is a response to the second research question: 'What can I learn from student teachers about cultivating an ILA to teaching mathematics in the FP using arts-based methods?'
Figure 4 shows two examples of collages compiled by student teachers in the module Mathematics in the Early Years. In these examples, the collages depict an ILA. For example, on the left-hand side of the yellow chart (the chart on the right) there is a picture of a birthday cake with the heading 'Happy birthday'. The student teachers indicated that this represented a celebration and that birthday celebrations promote socialisation and link with the Life Skills learning area. They also suggested that the image represented the age of the learners and their dates of birth, which linked with numbers, which are pivotal in the acquisition of mathematical skills.

Figure 5 shows the two concept maps that were created by the student teachers. Different keywords and phrases were grouped together in the concept maps to show the links within the ILA concepts. It was interesting to note how the students were able to 'move from written analytic text to the visual and back again' (Butler-Kisber \& Poldma 2010).
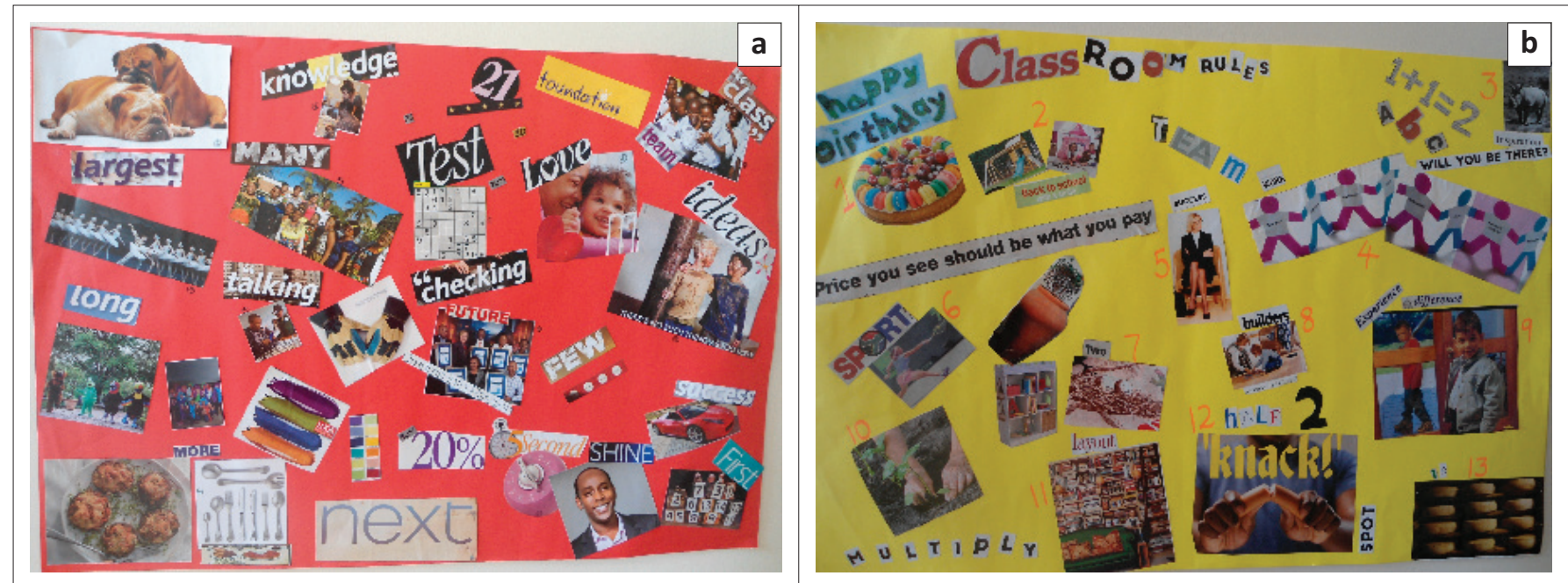

FIGURE 4: Collages $a$ and $b$ depicting an integrated learning approach.

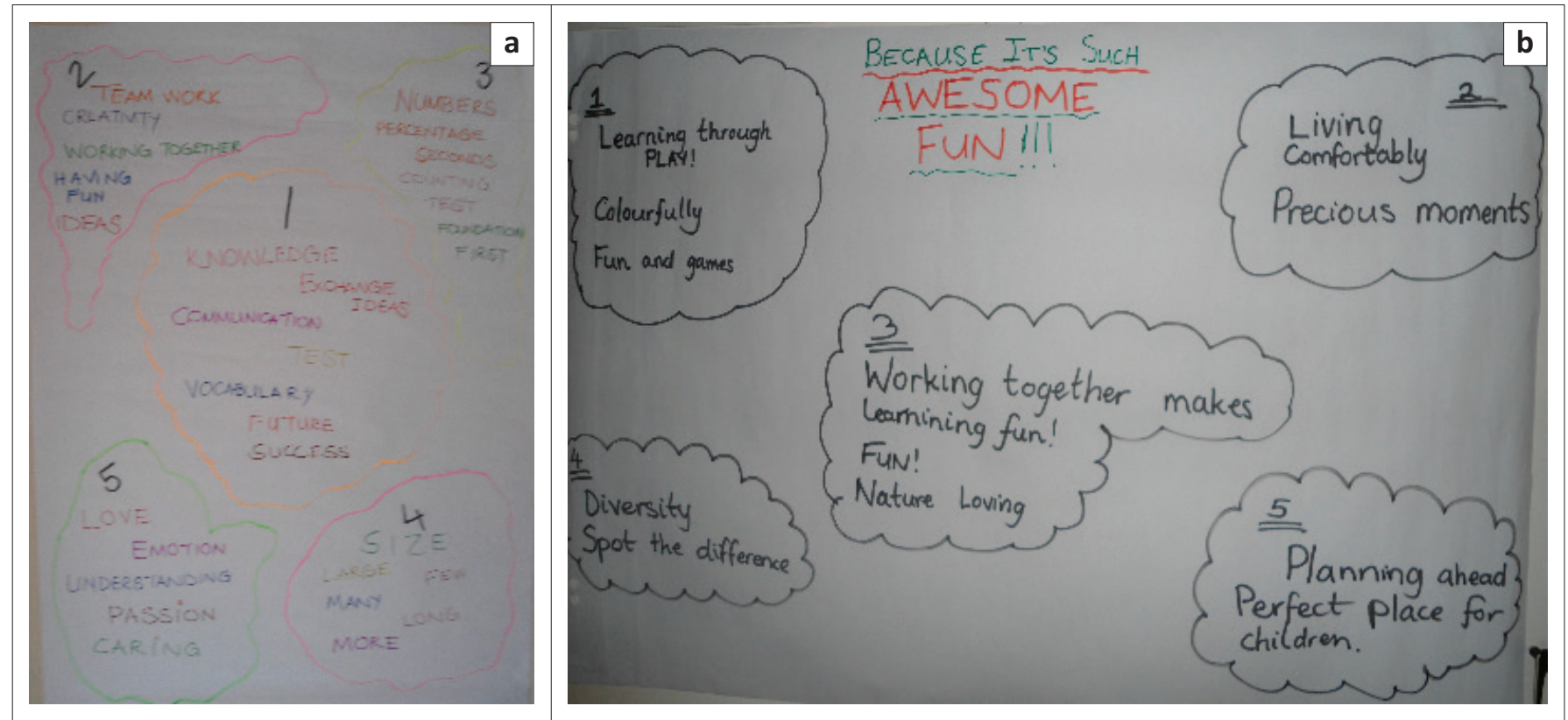

FIGURE 5: Concept maps created by student teachers in a and b. 
For example, numerical and other concepts depicted by the images in Figure 4 (such as the number of dogs, many people wearing traditional attire, a long queue of ballerinas and a comparison of the cutlery items in the collage) are captured in the concept map on the left in Figure 5. Concepts such as large, many, long and more that emerged were grouped together (Group 4) to represent measurement concepts.

During the process of concept mapping, I was able to help the students integrate ideas of an ILA that were sometimes difficult to put into words (Butler-Kisber \& Poldma 2010). For example, through my guidance the students were able to link the concepts of 'fun' and 'games' with the theme 'learning through play' in Figure 5 above (concept map on the right).

In the 15 years that I had worked as a teacher educator, I had never before embarked on arts-based methods, so I was somewhat apprehensive to use this approach. However, when I taught this module I learned more about my students through my interaction with them. For example, I learned that many would embrace the celebration of family connectedness such as birthdays and family get-togethers and that they could effectively utilise this knowledge to teach their learners numerical values, dates and counting skills. In turn, the students learned that family connectedness is an important element of prior knowledge that they can utilise to teach their learners.

Moreover, the arts-based lessons offered hands-on creative tools from a cultural context that helped the students to better grasp the concepts I was trying to teach (Samaras 2011). Because I was trying this for the first time I was nervous, but I learned that it was possible and 'doable'. Weber (2014) argues that although arts-based approaches are used for a wide range of purposes, they are highly useful in self-study education. I learned that for so many years as a teacher educator I had been using other learner-centred methods such as presentations and group discussions yet I had never ventured into an arts-based approach as I had thought these activities were for artistic people. When I embarked on this journey, I was forced out of my comfort zone - and what an amazing experience it proved to be!

Through this experience, I learned that student teachers need to be equipped with knowledge and hands-on experience of how integration should occur in mathematics teaching and learning in the FP, as well as how important placing emphasis on social and cultural practices is (Dimitriadis \& Kamberelis 2006). The choice of using artistic endeavours such as creating collages was beneficial to my students as it made the teaching of mathematical concepts fun. One of my journal entries reads as follows:

Admittedly, I was worried when I first introduced the concept of creating collages as the students appeared unresponsive. However, as I mingled with the groups and explained what they needed to do and why, they began to understand the concept and gained confidence to tackle the task. It was rewarding for me to see their excitement and sense of achievement when the collages were completed. (Kortjass 2016)
Butler-Kisber and Poldma (2010) suggest that students are excited when confronted with such a task and that they will gain confidence once they have achieved what they set out to do. I concur with this view as using a visual media approach was both challenging and rewarding. Moreover, by modelling how to utilise this strategy I was given valuable opportunities to interact with my students and I came to know them better, which improved my relations with them.

However, undertaking this project with the students also made me vulnerable, but in my vulnerability I learned about myself. For example, I learned that I could actually be creative regardless of the fact that I am not an artist. I also learned more about the classroom environment and how to teach my students to make it even more attractive, challenging and learner-centred. I understood my students through meaningful interactions with them. For example, I learned that most students were learning concepts, such as 'conservation' and 'subitising', for the first time. Lee (2014) notes that the classroom environment is part of a sociocultural dimension that is neither culture nor context free. Therefore, regardless of our differences, I got to know the students better, and going forward was easier as I soon started to understand the problems they experienced regarding understanding and teaching mathematical concepts, because mathematics is labelled as a difficult subject.

This process also made me think about how we assess students. In most cases we assess students when we do not really know them. I was afforded the opportunity to know them better and to interact with them in order to understand their struggles and misconceptions in relation to mathematics. Collaging was helpful in conceptualising ILA by presenting it differently in order to get a better understanding of it (Butler-Kisber \& Poldma 2010). This was a process that taught me to be patient and not to take things for granted, especially when working with first-year students. For example, at the beginning of the project the students tended to focus on aspects other than mathematics. I had to be aware of this and I had to ensure that mathematics remained the focus during the implementation of this approach.

\section{Learning about integrated learning approach by working with critical friends}

This section addresses my response to my third question: 'What can I learn from working with critical friends about cultivating an ILA for the teaching of mathematics in the FP?' I discussed my experiences with critical friends and also presented the self-study approach at a workshop to a group of colleagues and at a national education conference.

From a sociocultural theoretical perspective, it is evident that collaboration with critical friends allowed me to gain support that assisted me in understanding my research. It also assisted me in evaluating my own teaching methodology in more depth. Samaras (2011:76) asserts that self-study researchers 'incorporate the viewpoints and perspectives of 
colleagues to gain alternative perspectives and ongoing support for their research'. I thus received positive feedback, which was beneficial in helping me to obtain new ideas and illuminations about my research and work.

To illustrate, a few comments that were offered by critical friends are presented in the following.

A positive comment from a critical friend related to the fact that it was a 'self-study' project, which allowed me to engage in in-depth reflection. She said:

... you seem to be doing a lot of reflection. And I think [this] as well some of [the] things you [will be] picking up in your next class, you enable you to do things differently. This is not just a class where you say to students 'Integrate ...' or whatever, but you are also doing a study of your own practice which makes it different from the way integration has [been] taught [before], where it has just been a teacher teaching. (Critical Friend 1, National Conference, October 2016)

This comment illuminated how the pilot study assisted me to better understand my role as a teacher educator who needed to encourage my students to implement an ILA. I learned increasingly from my experiences and I started doing things differently as the semester progressed. Samaras (2010) argues that Vygotsky maintained that we learn through others and that mental processes can be understood if we comprehend tools that intercede them. I was thus not just telling the students to use the ILA, but I was studying my own teaching practices and methodology as well.

Another critical friend raised the question whether the ILA was an established approach or an experimental approach in South Africa. My close perusal of the relevant policy documents helped me to articulate that an ILA is emphasised in the new prescribed curriculum for the FP, especially in the early grades, and that it was an important approach to ensure that learners gain an understanding of the connections among the different learning areas. This was further validated by a critical friend, who said:

'It [ILA] is one of the values underpinning the CAPS curriculum'. (Critical Friend 2, Self-Reflexive Workshop, June 2016)

I also had to think about the principles of integration to ensure that mathematics teaching and learning did not get lost in the process of the ILA. This was prompted by another critical friend, who said:

'Just on the idea of what we do so that mathematics does not get lost - I just want to find out if you have thought about engaging the student teachers about the principles of that'. (Critical Friend 3, National Conference, October 2016)

The comments and the questions I received in response to my presentations were invaluable. These contributions validated what Samaras (2011) affirms about the significance of critical friends in helping one to gain new perspectives in understanding one's study. As noted by Schuck and Russell (2005:108), one problematic issue of self-study concerns 'the difficulty of assessing one's own practice and reframing it'.
A deeper understanding of ILA became possible through the use of essential feedback from critical friends who offered suggestions on how I could improve my practices as a teacher educator in early childhood mathematics. I realised that it was essential to constantly reflect on my practices and to explore new ways of teaching mathematics. As suggested by Schuck and Russel (2005:115), the fact that I reflected on what my critical friends said and that I valued and interpreted their comments 'led to some changes in my practice'. For example, I had to reconsider my lesson plans and embark on techniques specifically geared towards teaching students about mathematics teaching in the FP through the use of an ILA in the hope of enabling and enhancing teaching and learning of this subject not only for the benefit of my students but also in the interest of the pedagogics they will adopt as teachers in the FP. In the process of presenting my research, I established 'new understandings about critical friendship, its benefits, and its challenges' (Schuck \& Russell 2005).

Even though it was difficult for me to put myself at the centre of my research, I found that self-study helped me to focus on myself, my growth and my development. However, at the beginning I felt I was being attacked and needed to defend myself. I needed to have an open mind when I consulted critical friends for feedback. Often we get feedback and we just shut out constructive comments because we feel we 'got it right' the first time. What I learned is that it does not matter how much we know or we think we know, there is always feedback that can help us to learn something else. In actual fact, we should look forward to such feedback as an exciting opportunity for learning, rather than seeing it as something negative that is a threat to our sense of being. However, I acknowledge that it is sometimes difficult to find and appreciate that space, especially if we see ourselves as experienced and influential educators. I thus humbly acknowledge that, as an FP mathematics teacher educator, I had thought that I was on the right track, but I realised that I needed to move further. The principles of ILA taught me that, as a teacher educator, I needed to read widely to extend my horizons. This assisted me in my teaching and in better understanding the concept of ILA. Delving into the principles of ILA through my reading made me think differently, because previously I had felt confident with this concept, yet Ihad not incorporated it adequately in practice. I acknowledge that it is a humbling experience to put oneself out there as a learner rather than as a 'knower'; however, the benefits are that I shall be constantly learning and extending my knowledge and expertise in the field of mathematics teaching in the FP.

\section{Strengths and limitations}

I am at the very beginning of this new journey. I am still struggling with the idea of ' $I$ ' and putting myself in a pivotal position. Throughout my interaction with my supervisor and my critical friends, I kept referring to 'the students' rather than to 'me'. However, the experience that I gained through this study brought me to the point where I can now acknowledge that this study was about me. I initially made 
the mistake of downplaying how I felt and thinking that my position was not important or pivotal. However, by embracing the sociocultural perspective, I have moved from thinking about students' learning to understanding my own learning. For me, this has been a profound learning experience that has allowed me to be transformed to the extent that I now understand that teaching students to teach mathematics in the FP should occur at a whole new level.

Working with critical friends also equipped me with knowledge and insight that contributed to my research and enhanced my insight. My own experiences prompted me to explore the mathematical strategies and concepts that student teachers struggle with and to discover what skills and knowledge I would need to better assist them. For example, I remember that when we played games during my childhood years, one of my friends could not catch. I now understand that she probably had an eye-hand coordination problem. By continuing with my reflections I shall therefore be better equipped to identify ways in which I can help my students to improve their teaching practice of mathematics in the FP.

\section{Conclusion}

Conducting this pilot study from within a sociocultural theoretical perspective guided me to reflect deeply on new approaches to teacher education, particularly with regard to the teaching and learning of mathematics in the FP. The importance of taking into consideration the cultural background and mathematical experiences of student teachers was invaluable. As a mathematics teacher educator in early childhood education (i.e. the FP), I came to realise how I could better understand my student teachers' thinking about mathematics concepts and how I could support them in teaching mathematical skills and mathematical reasoning in their classes one day. I had to abandon my comfort zone and learn from a position of vulnerability, which was new and frightening. However, I learned about myself and about the pedagogy of what I was required to teach. I also learned that my student teachers and I were creative, even if we were not artists. I was able to embrace constructive critiques from friends, which challenged and channelled my thinking. All things considered, I learned through various interactions with others, namely colleagues and students. Based on my experiences, I strongly recommend that teacher educators consider engaging in self-study research, which may include art-based self-study methods. Teacher educators should reflect critically on their practices and embrace change for the benefit of their students and, ultimately, for the benefit of the learners.

\section{Acknowledgements}

I gratefully acknowledge my first-year students, who contributed to the generation of the data produced in this project. I appreciatively acknowledge my supervisor and my colleagues in their roles of critical friends, who provided valuable feedback in making this project successful. I gratefully acknowledge funding from the University of KwaZulu-Natal (UKZN) Teaching and Learning Office (UTLO) Teaching and Learning Innovation and Quality Enhancement Grant (TLIQEG). I thankfully acknowledge the peer reviewers for their helpful feedback.

This publication has been developed through the Teaching and Learning Development Capacity Improvement Programme which is being implemented through a partnership between the Department of Higher Education and Training and the European Union.

\section{Competing interests}

The author declares that she has no financial or personal relationships which may have inappropriately influenced her in writing this article.

\section{References}

Adamu, A.U., 2003, 'The concept of curriculum integration: Its meaning, scope and modalities', 1-15. Paper presented at the Workship on Integrating Qur'anic Education, held at Arewa House, Kaduna, Nigeria, March 14, 2003.

Berk, L.E., 2013, Child development, Pearson, Boston, MA.

Butler-Kisber, L. \& Poldma, T., 2010, 'The power of visual approaches in qualitative inquiry: The use of collage making and concept mapping in experiential research', Journal of Research Practice 6, 1-16.

Conkbayir, M. \& Pascal, C., 2016, Early childhood theories and contemporary issues: An introduction, Bloomsbury, London.

Department of Basic Education, 2011, Curriculum and assessment Policy Statement Grades R-3: Life skills, Government Press, Pretoria.

Department of Higher Education and Training, 2015, Revised policy on minimum requirements for teacher education qualifications, Government Press, Pretoria.

Dimitriadis, G. \& Kamberelis, G., 2006, 'Lev Semenovich Vygotsky', Theory for Education, Routledge, New York.

Gerdes, P., 1998, 'On culture and mathematics teacher education', Journal of Mathematics Teacher Educational 1, 33-53. https://doi.org/10.1023/A:1009955031429

Hughes, M., 1986, Children and number: Difficulties in learning mathematics, Basi Blackwell, Oxford

Kortjass, M.D., 2016, Journal entry, 22 February.

LaBoskey, V.K., 2004, 'The methodology of self-study and its theoretical underpinnings', in J.J. Loughran, M.L. Hamilton, V.K. LaBoskey, \& T Russell (eds.), Internationa handbook of self-study of teaching and teacher education practices, vol. 1. pp. handbook of self-study of teaching and teacher educ
817-869, Dorchrecht, Kluwer Academic Publishers.

Lake, K., 1994, Integrated curriculum, Oregon, Northwest Regional Education Laboratory (NWREL).

Lee, Y.C., 2014, 'Teaching and sociocultural perspectives', in R. Gunstone (ed.), Encyclopedia of Science Education, pp. 1038-1041, Dordrecht, Springer.

Mweli, P., 2018, 'Indegenous stories and games as approaches to teaching within the classroom', in I. Eloff \& E. Swart (eds.), Understanding educational psychology, pp. 94-101, JUTA, Cape Town.

Nieuwenhuis, J., 2010, 'Introducing qualitative research', in K. Maree (ed.), First steps in research, pp. 99-117, Van Shaik Publishers, Pretoria.

Nkopodi, N. \& Mosimege, M., 2009, 'Incorporating the Indegenous Game of morabaraba in the learning of Mathematics', South African Journal of Childhood Education 29, 377-392.

Ramani, G.B. \& Eason, S.H., 2015, 'It all adds up: Learning early math through play and games', Phi Delta Kappan 96, 27-32. https://doi.org/10.1177/0031721715583959

Samaras, A., 2011, Self-study teacher research: Improving your practice through collaborative inquiry, Sage, London.

Samaras, A.P., 2010, 'Explorations in using arts-based self-study methods', International Journal of Qualitative Studies in Education 23, 719-736. https://doi. org/10.1080/09518390903426212

Schuck, S. \& Russell, T., 2005, 'Self-study, critical friendship, and the complexities of teacher education', Studying Teacher Education 1, 107-121. https://doi. org/10.1080/17425960500288291

Weber, S., 2014, 'Arts-based self-study: Documenting the ripple effect', Perspectives in Education 32, 8-20. 